\title{
DIDÁTICA DA LITERATURA: PROBLEMATIZAÇÃO DE UMA TENDÊNCIA EM VIAS DE HEGEMONIZAÇÃO
}

\author{
DIDÁCTICA DE LA LITERATURA: PROBLEMATIZACIÓN DE UNA TENDENCIA A \\ LA HEGEMONIZACIÓN
}

\author{
DIDACTICS OF LITERATURE: PROBLEMATIZING A TREND TOWARD \\ HEGEMONY
}

\author{
Maria Amélia DALVI ${ }^{1}$ \\ Rosiane de Fátima PONCE ${ }^{2}$
}

RESUMO: À luz da epistemologia materialista histórica, investigamos como as chamadas "Estratégias de Leitura" têm sido apresentadas e utilizadas em pesquisas científicas e em documentos oficiais concernentes à interface educação e literatura; demonstramos, com base em análises de dados objetivos, que, ao longo de mais de uma década, ela vem se ampliando e encontra-se em construção de hegemonia. Buscamos compreender tal processo, instituindo, como marco decisivo, sua chegada aos documentos oficiais (que, no caso concreto em estudo, orientam o processo de educação escolar a partir de uma base nacional curricular, comum às redes públicas e privadas). Em seguida, problematizamos a incorporação das "Estratégias de Leitura" no texto da Base Nacional Comum Curricular; nas conclusões, apontamos que, para resolver os problemas do ensino de leitura no Brasil, e particularmente do ensino de leitura literária, o trabalho pedagógico orientado pela "internalização e automatização" de estratégias (meta)cognitivas de leitura precisa ser superado.

PALAVRAS-CHAVE: Estratégias de leitura. Base Nacional Comum Curricular (documentos oficiais). Leitura. Materialismo histórico e dialético. Didática da literatura.

RESUMEN: A la luz de la epistemología materialista histórica, investigamos cómo se han presentado y utilizado las llamadas "Estrategias de Lectura" en la investigación científica y en los documentos oficiales relativos a la interfaz educación y literatura; demostramos, a partir del análisis de datos objetivos, que a lo largo de más de una década se ha ido expandiendo y está en construcción de hegemonía. Buscamos comprender este proceso, estableciendo, como hito decisivo, su llegada a los documentos oficiales (que, en el caso concreto que estudiamos, orientan el proceso de educación escolar desde una base curricular nacional, común a las redes públicas y privadas). Luego, problematizamos la incorporación de las "Estrategias de Lectura" en el texto de la Base Curricular Nacional Común; en las conclusiones, señalamos que, para resolver los problemas de la enseñanza de la lectura en Brasil, y en particular la enseñanza de la lectura literaria, es necesario superar el trabajo

\footnotetext{
${ }^{1}$ Universidade Federal do Espírito Santo (UFES), Vitória - ES - Brasil. Professora Adjunta no Programa de Pós-Graduação em Educação e no Programa de Pós-Graduação em Letras. Doutorado em Educação (UFES). ORCID: https://orcid.org/0000-0002-8729-2338. E-mail: dalvimariaamelia@gmail.com

${ }^{2}$ Universidade Estadual Paulista (UNESP), Presidente Prudente - SP - Brasil. Professora no Departamento de Educação e Coordenadora do grupo de estudos e pesquisas (GEDHEE/UNESP/FCT). Doutorado em Educação (PUC/SP). ORCID: https://orcid.org/0000-0001-7138-3086. E-mail: poncef.rosiane@gmail.com
} 
pedagógico guiado por la "internalización y automatización" de las estrategias (meta) cognitivas de lectura.

PALABRAS CLAVE: Estrategias de lectura. Base Curricular Nacional Común (documentos oficiales). La lectura. Materialismo histórico y dialéctico. Didáctica de la literatura.

ABSTRACT: In the light of the historical materialist epistemology, it investigates how the socalled "Reading Strategies" have been presented and used in scientific research and official documents concerning the interface education and literature; based on the analysis of objective data, it demonstrates that, for over a decade, it has been expanding and is currently building hegemony. It seeks to understand this process, establishing, as a decisive landmark, its arrival to official documents (which, in the concrete case under study, guide the school education process from a national curricular base, common to public and private networks). Then, it problematizes the incorporation of "Reading Strategies" in the text of the Common National Curricular Base; in the conclusions, it points out that, to solve the problems of reading education in Brazil, and particularly the teaching of literary reading, the pedagogical work guided by the "internalization and automatization" of (meta)cognitive reading strategies needs to be overcomed.

KEYWORDS: Reading strategies. Common National Curricular Base (official documents). Reading. Historical and dialectical materialism. Didactics of literature.

\section{Considerações iniciais}

Este trabalho problematiza uma tendência adotada em pesquisas científicas e em orientações/bases curriculares (consubstanciadas em documentos oficiais) para o ensino de literatura; visa responder ao questionamento sobre a pertinência e consistência de tal tendência no campo da Didática da Literatura, considerando-se a realidade objetiva. Para tanto, apresenta a perspectiva do ensino de literatura à luz das "Estratégias de Leitura" em seus próprios termos e, em seguida, a analisa à luz de pressupostos materialistas históricos e dialéticos.

Considerando sua presença na Base Nacional Comum Curricular, bem como sua presença no âmbito acadêmico, é evidente que se trata de uma perspectiva "em vias de hegemonização" - aqui entendida em conformidade com o pensamento de Gramsci (1978a; 1978b), para quem a noção de "hegemonia" propõe uma nova relação entre estrutura e superestrutura, recusando o determinismo da primeira sobre a segunda e argumentando em favor da centralidade das superestruturas na análise das sociedades avançadas. Conforme Gruppi (1991) e Macciochi (1976), Gramsci foi o teórico marxista que mais insistiu nessa questão; por isso tomamos seu pensamento para discutir uma perspectiva em voga para o 
trabalho pedagógico com a leitura, que consideramos, como já dito, em vias de hegemonização.

Para o filósofo italiano, a ideologia aparece como constitutiva das relações sociais, de modo que a construção de um novo momento histórico requer sua análise. Conforme Alves (2010, p. 74-75):

Gramsci afirma que é muito comum um determinado grupo social, que está numa situação de subordinação com relação a outro grupo, adotar a concepção do mundo deste, mesmo que ela esteja em contradição com a sua atividade prática. Ademais, ele ressalta que esta concepção do mundo imposta mecanicamente pelo ambiente exterior é desprovida de consciência crítica e coerência, é desagregada e ocasional. Dessa adoção acrítica de uma concepção do mundo de outro grupo social, resulta um contraste entre o pensar e o agir e a coexistência de duas concepções do mundo [...]. Gramsci (1978a, p. 15) conclui, portanto, que "não se pode destacar a filosofia da política; ao contrário, pode-se demonstrar que a escolha e a crítica de uma concepção de mundo são, também elas, fatos políticos". [...] Para Gramsci, a consciência crítica é obtida através de uma disputa de hegemonias contrastantes, primeiro no campo da ética, depois no âmbito político, culminando, finalmente, numa elaboração superior de uma concepção do real.

É necessário advertir que, quando falamos de uma tendência em "vias de hegemonização", não necessariamente tomamos o mesmo interesse de Gramsci, que desenvolvia uma tese sobre como a classe trabalhadora ocidental poderia construir uma hegemonia que poderia levá-la à tomada do poder. Utilizamos o conceito de hegemonia tendo em mente que investigamos como uma noção pedagógica (não necessariamente articulada aos interesses da classe trabalhadora) constrói de "fora para dentro" sua hegemonia, estabelecendo-se como hegemônica (ou "em vias de hegemonização") quando chega aos documentos oficiais do Estado (que, no caso concreto em estudo, orientam o processo de educação escolar a partir de uma base nacional curricular, comum a todas as redes e instituições).

De acordo com Gramsci (1978a; 1978b), a ampliação da base social e o estabelecimento de um aparato hegemônico acontece por meio de um sistema de alianças, de modo que a questão da hegemonia não deve ser entendida grosseiramente, a partir da ideia de subordinação do grupo mais frágil na correlação de forças com o grupo hegemônico; pelo contrário, a produção da hegemonia pressupõe que se leve em conta os interesses dos grupos sobre os quais a hegemonia será exercida. Por isso, entendemos que a construção de uma hegemonia no campo da educação escolar requer o convencimento dos professores de que, ao adotar tal ou qual orientação teórica para a prática pedagógica, estarão contribuindo para seus 
objetivos como classe profissional (e, consequentemente, como classe que vive do trabalho), a saber, a melhor formação dos estudantes.

Por isso mesmo, a discussão aqui não incide em uma crítica aos profissionais da educação que adotam tal ou qual tendência para orientar seu trabalho, ou seja, não "fulanizamos" o debate - queremos, antes, situá-lo no horizonte do exercício do pensamento científico e filosófico criticamente orientado, que é requerido aos intelectuais orgânicos. Assim, tendo em vista a necessidade de desvelamento ideológico que se imiscui na proposta de adoção das "Estratégias de Leitura" no âmbito da Didática da Literatura, justifica-se este trabalho.

\section{"Estratégias de Leitura" como tendência em vias de hegemonização}

Por que as "Estratégias de Leitura" seriam uma tendência em vias de hegemonização? Vamos a evidências objetivas: no que concerne à presença das chamadas "Estratégias de Leitura" no âmbito acadêmico, a base do "Google Scholar"3 informa que, entre 2015 e 2019 (portanto, os cinco anos anteriores ao momento de escrita deste texto), essa expressão, combinada com a palavra-chave "Literatura", recebeu 5.580 citações. Esse dado quantitativo, por si, faz notar que se trata de expressão amplamente utilizada nos meios universitários, em artigos, ensaios e materiais de formação chancelados na/pela esfera de atividade correspondente.

O "Catálogo de Teses e Dissertações da Capes", que reúne os trabalhos desenvolvidos em nível de pós-graduação no Brasil (portanto, trabalhos de pesquisa avançada supostamente - com maior profundidade e mais alentados que artigos, ensaios e materiais de formação), a partir dos mesmos parâmetros da busca anterior, informa 230 ocorrências de "Estratégias de Leitura" como termo-chave. Tais ocorrências, no Catálogo, estão concentradas nos cursos de mestrado acadêmico e mestrado profissional, sendo 2016 o ano que reúne o

\footnotetext{
3 Consulta realizada pela última vez em 20 de outubro de 2020, às $10 \mathrm{~h}$ (Disponível em: https://scholar.google.com/scholar?q=\%22estrat $\% \mathrm{C} 3 \% \mathrm{~A} 9$ gias $+\mathrm{de}+\mathrm{leitura} \% 22+\% 2 \mathrm{~B}+$ literatura\&hl=pt-

BR\&as_sdt $=1 \% 2 \mathrm{C} 5 \&$ as ylo=2015\&as yhi=2019. Acesso em: 21 out. 2020). Trata-se do buscador acadêmicocientífico mais utilizado no Brasil, para mapeamento de citações e que, de acordo com o Portal de Periódicos da Coordenação de Aperfeiçoamento de Pessoal de Nível Superior (órgão oficial do governo federal), gera o chamado "fator H", utilizado como métrica para o impacto científico de pesquisadores e cientistas (Disponível em: https://www.periodicos.capes.gov.br/? option $=$ com_pnews\&component $=$ Clipping\&view $=$ pnewsclipping\&cid $=970 \& m n=0 \#: \sim:$ text $=\mathrm{O}$ $\% 20 \% \mathrm{C} 3 \%$ ADndice $\% 20$ trata\%2Dse $\% 20 \mathrm{do}, \mathrm{n} \% \mathrm{C} 3 \% \mathrm{~A} 3 \mathrm{o} \% 20$ seriam $\% 20$ considerados $\% 20$ no $\% 20 \mathrm{c}$ $\%$ C3\%A1lculo. Acesso em: 21 out. 2020). Ressalte-se que o Google Scholar (ou Google Acadêmico) é um buscador privado, vinculado a uma corporação internacional.

${ }_{4}$ Consulta realizada pela última vez em 20 de outubro de 2020, às $11 \mathrm{~h}$ (Disponível em: https://catalogodeteses.capes.gov.br/catalogo-teses/\#!/. Acesso em: 21 out. 2020).
} 
maior número de trabalhos recuperados a partir deste descritor. As dissertações e teses ali localizadas estão distribuídas majoritariamente entre as seguintes instituições: Pontifícia Universidade Católica de São Paulo, Universidade Federal de Minas Gerias e Universidade de São Paulo.

Do ponto de vista dos sujeitos em atividade no campo acadêmico para o desenvolvimento e a consolidação dessa tendência, o levantamento realizado a partir do Catálogo da Capes aponta que os orientadores mais frequentes no conjunto de 230 trabalhos recuperados são Beatriz dos Santos Feres, Renata Junqueira e Maria de Lourdes Guimarães Carvalho, atuantes nas áreas de conhecimento "Língua Portuguesa", "Letras" e "Educação". Os membros de banca mais presentes na avaliação das dissertações e teses recuperadas por meio desse levantamento são, respectivamente, Renata Junqueira de Souza, Dagoberto Buim Arena e Luiz Antônio Ferreira.

Levando em conta tais dados e buscando uma consistência na apresentação da perspectiva teórica das "Estratégias de Leitura", ela será apresentada a partir da obra Ler e compreender: estratégias de leitura (MENIN et al., 2010), pois nela dois dos autores indicados pelo Catálogo como fundamentais ao desenvolvimento e consolidação dessa perspectiva a partir do campo acadêmico comparecem como organizadores e autores dos textos. Assim, evitamos o risco de tomar como referencial para a apresentação conceitual eventuais divulgadores ou diluidores pouco afeitos ao efetivo desenvolvimento e disseminação da noção em foco.

No que concerne ao âmbito das propostas oficiais, é importante ressaltar que essa perspectiva é explicitamente citada pelo menos dezoito vezes na nova Base Nacional Comum Curricular (BNCC) (BRASIL, 2018). No subitem "Língua Portuguesa no ensino fundamental - anos iniciais: práticas de linguagem, objetos de conhecimento e habilidades", comparece pela primeira vez no seguinte trecho: “Assim, no Ensino Fundamental - Anos Iniciais, [...] no eixo Leitura/Escuta, amplia-se o letramento, por meio da progressiva incorporação de estratégias de leitura em textos de nível de complexidade crescente" (BRASIL, 2018, p. 89, grifo nosso).

Em seguida, as "Estratégias de Leitura" comparecem como "objeto de conhecimento" do "Campo artístico-literário", no quadro síntese da proposta para o ensino de Língua Portuguesa no $6^{\circ}$ e $7^{\circ}$ anos e, depois, no $8^{\circ}$ e $9^{\circ}$ anos (BRASIL, 2018, p. 168-186); e comparecem no correspondente rol de "Habilidades" a serem desenvolvidas pelos estudantes dessa disciplina nesses anos de estudo: 
(EF67LP28) Ler, de forma autônoma, e compreender - selecionando procedimentos e estratégias de leitura adequados a diferentes objetivos e levando em conta características dos gêneros e suportes -, romances infantojuvenis, contos populares, contos de terror, lendas brasileiras, indígenas e africanas, narrativas de aventuras, narrativas de enigma, mitos, crônicas, autobiografias, histórias em quadrinhos, mangás, poemas de forma livre e fixa (como sonetos e cordéis), vídeo-poemas, poemas visuais, dentre outros, expressando avaliação sobre o texto lido e estabelecendo preferências por gêneros, temas, autores. [...]

(EF89LP33) Ler, de forma autônoma, e compreender - selecionando procedimentos e estratégias de leitura adequados a diferentes objetivos e levando em conta características dos gêneros e suportes - romances, contos contemporâneos, minicontos, fábulas contemporâneas, romances juvenis, biografias romanceadas, novelas, crônicas visuais, narrativas de ficção científica, narrativas de suspense, poemas de forma livre e fixa (como haicai), poema concreto, ciberpoema, dentre outros, expressando avaliação sobre o texto lido e estabelecendo preferências por gêneros, temas, autores (BRASIL, 2018, p. 169-187, grifo nosso).

As demais ocorrências da expressão "Estratégias de Leitura" se localizam na parte da BNCC referente à Língua Inglesa; consignam, de acordo com a leitura contextualizada do documento, um entendimento diferente daquele realizado na parte referente à Língua Portuguesa, pois enfatizam que elas se aplicam não à leitura autônoma, à compreensão de textos literários, à expressão de avaliação ou ao estabelecimento de preferências por gêneros, temas e autores (como acontece na parte referente à Língua Portuguesa, citada anteriormente); mas são entendidas como recursos (meta)cognitivos de aproximação inicial dos textos a serem lidos em quaisquer esferas de atividade humana (e não, privilegiadamente, da esfera literária).

No que concerne à Língua Inglesa, as "Estratégias de Leitura" aparecem como uma "Unidade Temática" (e não como "Objeto de Conhecimento", como acontece em Língua Portuguesa), vinculada aos seguintes "Objetos de Conhecimento": "Hipóteses sobre a finalidade de um texto" e "Compreensão geral e específica: leitura rápida (skimming, scanning)", para o $6^{\circ}$ ano; "Compreensão geral e específica: leitura rápida (skimming, scanning)" e "Construção do sentido global do texto", para o $7^{\circ}$ ano; "Construção de sentidos por meio de inferências e reconhecimento de implícitos", para o $8^{\circ}$ ano (BRASIL, 2018, p. 256); e "Recursos de persuasão" e "Recursos de argumentação", para o $9^{\circ}$ ano (BRASIL, 2018, p. 260).

Já no campo das "Práticas de Estudo e Pesquisa", ao final do documento, as "Estratégias de Leitura" comparecem mencionadas explicitamente na habilidade identificada como “(EM13LP28) Organizar situações de estudo e utilizar procedimentos e estratégias de 
leitura adequados aos objetivos e à natureza do conhecimento em questão" (BRASIL, 2018, p. 517, grifo nosso).

Face a esse conjunto de dados, emerge como inequívoco o processo de construção de uma hegemonia das "Estratégias de Leitura" no campo da Didática da Literatura, no Brasil. Desse modo, podemos dizer que se trata de uma tendência "em vias de hegemonização" pois amplamente recorrente no campo intelectual e, a partir daí, assegurada nos documentos oficiais de Estado orientadores do trabalho pedagógico nas redes pública e privada de educação escolar.

Um outro elemento, ainda, deve ser considerado: há uma flutuação ou instabilidade quanto ao entendimento do que sejam "Estratégias de Leitura". Seria um referencial teóricometodológico (como citado em alguns dos trabalhos constantes do Catálogo da Capes) e, portanto, delinearia um horizonte epistemológico para a produção de conhecimento nos campos de Letras, Linguística e Educação? Seria uma metodologia de ensino? Seria algo a ser incorporado à "ampliação do Letramento" (como aparece na primeira ocorrência na BNCC)? Seria um objeto de conhecimento do campo artístico-literário? Seria parte do processo de compreensão de textos (processo que é explicado nos itens EF67LP28 e EF89LP33 da BNCC como sendo a capacidade de selecionar "procedimentos e estratégias de leitura adequados a diferentes objetivos e levando em conta características dos gêneros e suportes")? Seria uma "unidade temática", como comparece na parte da BNCC referente à Língua Inglesa?

Diante de tantos questionamentos, e face às inconsistências demonstradas já no documento basilar para o currículo de toda a educação básica, nosso objetivo é bem modesto: esclarecer em seus próprios termos como se apresenta a perspectiva das "Estratégias de Leitura" no Brasil; para tanto, conforme já anunciado, vamos recorrer a uma publicação organizada por autores de referência, com base nos parâmetros já explicitados anteriormente.

A nossa atenção principal será dirigida às concepções da intelectual estadunidense que introduziu, por meio de palestras, cursos e colaborações de pesquisa as "Estratégias de Leitura" em nosso país, e que foi convidada pelos organizadores da publicação para prefaciar a obra: o que evidencia que os intelectuais brasileiros concedem a ela reconhecimento e prestígio - já que, como paratexto, o papel de um prefácio é não apenas apresentar a obra, mas, por meio de um argumento de autoridade intelectual, reforçar a pertinência e a legitimidade do conteúdo da publicação.

As "Estratégias de Leitura" na visão da pesquisadora que formou os primeiros quadros brasileiros para seu desenvolvimento e disseminação 
A obra Ler e compreender: estratégias de leitura, organizada por Menin et al. (2010), se estrutura em cinco partes: um prefácio (assinado por Lynn Davis, identificada como professora associada na área de Educação da Plymouth State University); os capítulos I (A literatura infantil como produção cultural e como instrumento de iniciação da criança no mundo da cultura escrita); II (Estratégias de leitura: para pensar alunos e compreender o que leem); e III (Avaliar atividades de leitura para quê?); e, enfim, um apêndice intitulado "Sugestões de livros para as estratégias de compreensão".

O prefácio informa que o livro decorre de uma pesquisa de três anos, iniciada em 2006, que teve por objetivo "levar a literatura infantil para a sala de aula e, dessa forma, envolver os alunos com os livros", e como objeto de investigação "a aplicabilidade do uso da literatura infantil no ensino de estratégias de compreensão textual desenvolvidas em programas de leitura em escolas primárias e secundárias" (DAVIS, 2010, p. 9). A prefaciadora (DAVIS, 2010, p. 9-11) relata que realizou uma palestra no Brasil e que retornou algum tempo depois para ministrar "uma série de minicursos para professores de escolas regulares e de universidades sobre estratégias de compreensão" (DAVIS, 2010, p. 10); informa que os estudos foram realizados com base no livro Strategies that Works (HARVEY; GOUDVIS, 2008 apud DAVIS, 2010, p. 10) - atualmente, na terceira edição, publicada em 2017.

Na sequência, a prefaciadora explicita sua concepção de leitura:

[...] eu não precisava falar a língua deles para perceber a paixão daqueles professores pela aprendizagem e pude constatar com que dedicação eles lutavam para melhorar o ensino da leitura. Nós concordávamos que ler é muito mais que decodificar palavras e responder a questões literais. Ler é uma questão de estratégia. Enfim, de se conectar com as personagens da história, fazer perguntas sobre coisas novas que o leitor aprendeu, fazer inferências para chegar a uma conclusão ou interpretar. De qualquer modo, leitores independentes e proficientes desenvolvem estratégias.

Como leitores proficientes, independentes, nós temos consciência de quando perdemos o foco e sabemos como superar nossa falta de compreensão. Nossas estratégias de fixação estão internalizadas, justamente por isso são automáticas. [...] Quando lemos usamos imagens mentais para nos ajudar a compreender as ações das personagens ou adquirir um novo conceito. Ao contrário de nós, muitas crianças das séries iniciais não utilizam estratégias de compreensão automaticamente. [...]

Os leitores proficientes envolvem-se na leitura porque desenvolveram muito bem habilidades e estratégias que lhes permitem atingir um alto nível de compreensão. $\mathrm{O}$ ensino de estratégias de compreensão ajuda os alunos a refletirem sobre o que leram e os instrumentaliza para um mergulho mais profundo no texto. [...] Aulas que efetivamente ajudam a desenvolver as estratégias promovem oportunidades para a prática da reflexão sob a orientação do professor, despertando nos alunos comportamentos desejados 
como a prática independente. Os alunos que internalizam as estratégias de compreensão tornam-se capazes de transferir seu conhecimento para gêneros diferentes e textos mais complexos. [...]

[...] Tem sido um privilégio trabalhar com esses dedicados educadores [Renata, Cyntia, Dagoberto e Ana Maria] cujo principal objetivo é criar ambientes de aprendizagem nos quais os alunos se tornam leitores proficientes e independentes (DAVIS, 2010, p. 9-11, grifo nosso).

Embora longa, a citação é necessária para contextualizar adequadamente e em seus próprios termos as "Estratégias de Leitura", a partir da visão da estudiosa estadunidense que formou os primeiros profissionais a partir dos quais essa perspectiva se desenvolveu e disseminou no Brasil. Para Davis (2010, p. 9-11), então: ler é uma questão de estratégias; leitores independentes e proficientes desenvolvem e aplicam estratégias e se envolvem com a leitura porque "desenvolveram muito bem habilidades e estratégias"; essas estratégias de leitura são internalizadas e, por isso, são automáticas; quando lemos usamos imagens mentais.

Quanto ao trabalho dos professores, para a autora, boas aulas de leitura "promovem oportunidades para a prática da reflexão", "despertando nos alunos comportamentos desejados"; e educadores dedicados têm como principal objetivo "criar ambientes de aprendizagem nos quais os alunos se tornam leitores proficientes e independentes" (DAVIS, 2010, p. 11). Tudo isso parece evidenciar uma refuncionalização de concepções pedagógicas que, em tese, teriam orientado o século XX: os professores, longe de ensinarem conteúdos e incidirem sobre a formação omnilateral dos estudantes, "promovem oportunidades", "despertam comportamentos" (bem à moda behaviorista) e "criam ambientes de aprendizagem" (DAVIS, 2010, p. 11).

No tocante ao objeto de conhecimento, é importante não deixar esquecido que Davis (2010) evidencia que sua contribuição ${ }^{5}$ para a formação dos primeiros quadros brasileiros articula-se inequivocamente ao desenvolvimento uma pesquisa inaugural realizada por Menin, Girotto, Buim e Souza entre 2006-2009, e cuja síntese foi publicada no livro que tomamos aqui como fonte.

$\mathrm{Na}$ aludida pesquisa, o objetivo era "levar a literatura infantil para a sala de aula e, dessa forma, envolver os alunos com os livros" e o objeto de investigação era "a aplicabilidade do uso da literatura infantil no ensino de estratégias de compreensão textual

\footnotetext{
${ }^{5}$ Adicionalmente, por meio de pesquisa nos currículos oficiais da Plataforma Lattes e por meio de notícia publicada no sítio eletrônico da Plymouth State University, localizamos a informação de que pelo menos uma das pesquisadoras brasileiras realizou um estágio (durante um ano sabático) junto à instituição a qual Lynn Davis é vinculada, desenvolvendo-se entre ambas uma intensa colaboração ao longo de anos (Disponível em: https://www.fosters.com/article/20080910/GJNEWS02/709107787. Acesso em: 21 out. 2020), inclusive com financiamento da Fundação de Amparo à Pesquisa do Estado de São Paulo (Disponível em: https://bv.fapesp.br/ pt/instituicao_exterior/2590/plymouth-state-university psu/?sort=nome\&group_by=type\&sort_intermed=-count. Acesso em: 21 out. 2020 ).
} 
desenvolvidas em programas de leitura em escolas primárias e secundárias" (DAVIS, 2010, p. 9). Não vamos avançar aqui na compatibilidade ou não entre o objetivo e o objeto enunciados. Restringir-nos-emos a indicar que nas afirmativas citadas: a) reconhece-se a crença, muito disseminada, de que o contato das crianças com a literatura infantil em contexto escolar é o principal fator (para não dizer único...) para que os sujeitos se "envolvam" com livros; e b) detecta-se uma visão de literatura instrumental, pois a literatura infantil seria usada no ensino de estratégias de compreensão textual.

Do ponto de vista de uma análise pedagógica, a noção de "envolvimento" (das crianças com livros) é inespecífica ou vazia, sem parâmetros que permitam julgar o que é uma pessoa "envolvida" ou não com livros e sem parâmetros que justifiquem porque isso seria desejável a ponto de constituir um legítimo objetivo educacional, razão pela qual parece pouco produtiva científica ou filosoficamente. Já do ponto de vista de uma análise estéticoliterária, parece suficientemente óbvia a impertinência de se reduzir a literatura infantil a um material didático cujo uso viria a ser julgado como "aplicável" (ou não) no ensino de estratégias de compreensão textual.

Note-se, por fim, um esvaziamento da função de transmissão de conteúdos escolares, pois mesmo nas poucas ocorrências da palavra "ensino" no prefácio de Davis (2010), ele é reduzido ao "ensino de estratégias de compreensão textual desenvolvidas em programas de leitura em escolas primárias e secundárias" - ou seja, não se ensinam conteúdos, com vistas ao desenvolvimento de capacidades e habilidades, mas se ensinam estratégias, ou seja, processos (meta)cognitivos. Trata-se, pois, de uma alusão à perspectiva de que na escola se deve "aprender a aprender" (ou a monitorar a própria aprendizagem), esvaziando-se os objetos de aprendizagem (ou seja, os conteúdos que deveriam ser apropriados e objetivados).

Tais estratégias, conforme Girotto e Souza (2010, p. 47), seriam: conexões, inferências, visualização, questionamento, síntese e sumarização - e tais nomenclaturas são assumidas pelas autoras na publicação que esquadrinhamos com a seguinte justificativa: "optamos por utilizar essas nomenclaturas, tendo em vista que temos por base o ensino dessas estratégias à luz da teoria metacognitiva dos norte-americanos referenciados neste texto".

\section{Uma análise das "Estratégias de Leitura" à luz da realidade objetiva}

Em relação à concepção de leitura decantada do pensamento de Davis (2010), o processo discursivo e dialógico não constitui a atividade de leitura, pois, se constituísse, ler implicaria não apenas produzir sentidos, mas assumir uma posição responsável e responsiva 
face ao discurso alheio. Nesse sentido, o uso, nos diferentes capítulos da publicação, de citações de autores de base materialista histórica e dialética tais como Bakhtin e Vigotski, parece constituir apenas um recurso estratégico para favorecer a aceitação das ideias ali apresentadas por eventuais leitores afinados com as contribuições desses autores, ou para diluir os conceitos que dão lastro à perspectiva defendida, tornando-os mais facilmente “assimiláveis".

Nas palavras da prefaciadora e principal disseminadora das "Estratégias de Leitura" em sua transplantação do contexto estadunidense para o contexto brasileiro, a leitura resumese a uma questão de se aprenderem ferramentas (meta)cognitivas de automonitoramento, pois "ler é uma questão de estratégia" e "como leitores proficientes, independentes, nós temos consciência de quando perdemos o foco e sabemos como superar nossa falta de compreensão" (DAVIS, 2010, p. 9-11). Tais estratégias precisariam não apenas ser internalizadas, mas automatizadas - de modo que se as aplique aos textos sem qualquer hesitação. Não haveria, pois, sequer dúvidas quanto a sua pertinência face à infinidade de textos e gêneros que circulam em inúmeras esferas de atividade humana.

Face à ideia de que leitores independentes e proficientes se envolvem com a leitura porque "desenvolveram muito bem habilidades e estratégias", é pertinente ressaltar um apagamento da dimensão cultural, econômica, histórica e social da leitura; nas palavras de Davis (2010), como vimos, não há menção ao fato de que as pessoas se tornam leitores independentes e proficientes por uma série de razões que não se restringem a questões (meta)cognitivas.

O acesso e a permanência em escolas públicas de qualidade, a existência de boas bibliotecas (acessíveis, com acervos planejados e com mediadores de leitura bem formados), a convivência familiar/comunitária em situações concretas de uso da leitura e da escrita, a possibilidade de aquisição dos materiais de leitura desejados e o usufruto deles pelo tempo necessário, a disponibilidade de tempo livre que possa ser usado para a leitura, a existência de espaços físicos adequados para a leitura (iluminados, claros, tranquilos), a formação e valorização profissional dos professores, que são os principais responsáveis pela transmissão da leitura e escrita de maneira sistematizada e intencional às crianças... enfim, nada disso é mencionado como requisito para a formação de leitores pela estudiosa estadunidense que atuou na disseminação das "estratégias de leitura" no Brasil, no prefácio à obra que constitui um marco significativo de pesquisa: “As informações presentes neste livro, resultantes desse projeto [de pesquisa], possuem potencial para suscitar mudanças. As descobertas desse grupo 
e esta publicação servirão como valiosa fonte tanto para professores ingressantes, quanto para veteranos" (DAVIS, 2010, p. 9).

Do ponto de vista dos elementos da realidade concreta, a hipótese aventada para os problemas atinentes ao ensino e aprendizagem da leitura foi o uso de livros didáticos "cujos scripts eram bastante específicos", a pouca disponibilidade de literatura infantil e o nãoensino de estratégias (meta)cognitivas:

[...] Durante minha visita [à Universidade Estadual Paulista, em Presidente Prudente - SP], descobri que a maior parte das aulas de leitura nas escolas brasileiras era ministrada por meio de livros didáticos com lições cujos scripts eram bastante específicos. Havia pouca literatura infantil disponível para essas aulas e, na maioria dos casos, não se ensinavam estratégias que possibilitassem o exercício da reflexão aos alunos.

Minha amiga Renata e seus colegas acreditavam que o uso exclusivo de manuais didáticos no ensino de leitura não preparava os alunos para uma leitura proficiente. Eles sabiam que os alunos precisavam de estratégias de compreensão específicas para se tornarem leitores independentes e para refletirem sobre o que liam (DAVIS, 2010, p. 9-10).

A oposição entre, de um lado, leitores proficientes e independentes e, de outro, nãoleitores ou leitores não-proficientes, tampouco perpassa as questões de classe, a se julgar pela posição assumida por Davis (2010). O que escapa à autora é que pessoas leem ou não leem não porque sejam capazes ou incapazes de fazer um monitoramento automatizado de seu próprio processo de leitura, mas por uma série de fatores vincados pela objetividade material.

O Brasil e o mundo detêm inaceitáveis índices de analfabetismo (de acordo com a CIA World Factbook, a taxa global de alfabetização de pessoas com mais de 15 anos é de 84,1\%; no Brasil esse índice é de 93,2\%) (INDEX MUNDI, 2020). Esses índices de analfabetismo se referem apenas a pessoas com mais de 15 anos: a situação brasileira, ao final do ciclo de alfabetização - planejado para se encerrar até os 8 anos de idade das crianças -, é dramática. Conforme o documento oficial da Política Nacional da Alfabetização (BRASIL, 2019, p. 10):

Segundo os resultados da Avaliação Nacional da Alfabetização (ANA), de 2016, 54,73\% de mais de 2 milhões de alunos concluintes do $3^{\circ}$ ano do ensino fundamental apresentaram desempenho insuficiente no exame de proficiência em leitura. Desse total, cerca de 450 mil alunos foram classificados no nível 1 da escala de proficiência, o que significa que são incapazes de localizar informação explícita em textos simples de até cinco linhas e de identificar a finalidade de textos como convites, cartazes, receitas e bilhetes.

Em escrita, 33,95\% estavam em níveis insuficientes (1, 2 ou 3). Embora o número não seja tão alto em comparação com leitura, percebe-se a gravidade do problema diante da descrição desses níveis: aproximadamente $680 \mathrm{mil}$ alunos de cerca de 8 anos estão nos níveis 1 e 2, o que quer dizer que não conseguem escrever "palavras alfabeticamente" ou as escrevem com desvios 
ortográficos. Quanto à escrita de textos, ou produzem textos ilegíveis, ou são absolutamente incapazes de escrever um texto curto.

A comparação dos resultados das edições de 2014 e de 2016 revela uma estagnação no desempenho dos alunos (INEP, 2018a). Além disso, percebese que a situação está muito distante daquela estabelecida pela meta 5 do Plano Nacional de Educação (PNE), a saber, alfabetizar todas as crianças, no máximo, até o final do $3^{\circ}$ ano do ensino fundamental.

O Brasil tem a $2^{\mathrm{a}}$ maior concentração de renda do mundo (de acordo com o Relatório de Desenvolvimento Humano da Organização das Nações Unidas, publicado em 09 de dezembro de 2019 , o $1 \%$ mais rico concentra $28,3 \%$ da renda total do País; e os $10 \%$ mais ricos no Brasil concentram 41,9\% da renda total). Isso significa que, para que tão poucos tenham tanto, a maior parte da população do país vive em condições miseráveis. Quanto a isso, é elucidativo o texto de uma matéria jornalística que expõe os dados de pesquisa produzida pelo Instituto Brasileiro de Geografia e Estatística concluída em 2019:

Apenas 2,7\% das famílias brasileiras concentraram quase $20 \%$ de todo o dinheiro recebido pelas famílias no País, entre 2017 e 2018. A informação é da Pesquisa de Orçamentos Familiares (POF), divulgada nesta sexta-feira 4 pelo Instituto Brasileiro de Geografia e Estatística (IBGE). Segundo a pesquisa, o total de famílias no Brasil é de aproximadamente 69 milhões. Desse número, 2,7\%, equivalentes a 1,8 milhão de famílias, têm um rendimento superior a 23 mil e 850 reais. Enquanto isso, 23,9\%, equivalentes a 16,4 milhões de famílias, recebem somente até 1.908 reais, correspondentes a dois salários mínimos.

[...] A pesquisa afirma que a renda média das famílias no Brasil é de 5.426 reais. No entanto, este cálculo soma o rendimento de todas das famílias, pobres e ricas, e forma uma média. Destes 5.426 reais da média, 1.080 reais vêm do rendimento das famílias mais ricas e apenas 297 reais vêm das famílias mais pobres. Ou seja, enquanto as famílias mais ricas (1,8 milhão) detêm $20 \%$ do rendimento total gerado no Brasil, as famílias mais pobres (16,4 milhões) ficam com apenas 5,5\%.

A pesquisa mostra ainda que, no rendimento das famílias que ganham até 1.908 reais mensais, $24,3 \%$ vem de transferências governamentais, como aposentadorias, pensões públicas e privadas, bolsas de estudos e programas sociais de transferência de renda. [...] Para o pesquisador José Mauro de Freitas Júnior, analista de gerência de Pesquisas de Orçamentos de Famílias do IBGE, o estudo mostra altos índices de desigualdade social no Brasil. "Quando você diz que 2,7\% das famílias contribuem com um percentual muito maior que a maioria esmagadora das famílias, você está dizendo que existe uma grande desigualdade. Imagina: $87 \%$ das famílias contribuem com $54 \%$ da renda média. Então, há uma desigualdade bastante grande" (OHANA, 2019, grifo do autor).

Considerando a realidade brasileira objetiva, não se pode esquecer que, no momento de escrita deste texto, o valor do salário mínimo vigente é de R\$1.045,00 (BRASIL, 2020), enquanto o Departamento Intersindical de Estatística e Estudos Socioeconômicos (DIEESE) calcula que "para sustentar uma família de quatro pessoas em agosto [de 2020], com dois 
adultos e duas crianças, o salário mínimo deveria ter sido de $\mathrm{R} \$ 4.536,12$. Esse valor corresponde a 4,34 vezes o mínimo atual" (ECONOMIA, 2020). Adicionalmente, de acordo com dados da Pesquisa Nacional por Amostragem de Domicílios (PNAD), no momento de escrita deste texto, em 2020, "a população subutilizada cresceu $15,7 \%$, chegando a $29,1 \%$, um total de 31,9 milhões de pessoas. Já a população fora da força de trabalho chegou a 77,8 milhões de pessoas, o maior contingente da série histórica [iniciada em 2012], com crescimento recorde" e "O número de postos de trabalho com carteira assinada no setor privado chegou ao mais baixo patamar da série histórica - 30,2 milhões de pessoas empregadas formalmente" (TV JORNAL, 2020). Os pais das crianças em nossas escolas estão passando dificuldades graves para pôr comida na mesa, para pagar o aluguel, para comprar materiais escolares e uniformes, para manter em dia a conta de energia que assegura luz para que se leia até mais tarde...

Esses problemas brasileiros - e aqui focamos apenas nos índices de analfabetismo e no insucesso da alfabetização de crianças; na concentração de renda; na incompatibilidade entre o salário mínimo recebido pela maioria dos trabalhadores e o mínimo necessário para viver com dignidade; no desemprego e subutilização da força de trabalho, com a retração do número de pessoas ocupadas e o crescimento de vínculos trabalhistas precários - não são novos, mas crônicos. Ou seja, já eram públicos e notórios na primeira década dos anos 2000; desse modo, é alarmante que, nas pesquisas desenvolvidas pelos estudiosos brasileiros, bem como na sua apresentação por uma intelectual estrangeira, não tenham sido levados em conta para pensar as causas do insucesso das crianças com a aprendizagem da leitura.

Sequer os problemas estruturais crônicos da educação nacional foram dimensionados, e as hipóteses aventadas recaíram sobre a má qualidade dos livros didáticos, na indisponibilidade de literatura infantil e no não domínio de estratégias (meta)cognitivas de monitoramento do próprio processo de leitura. Não queremos, com isso, afirmar que tais questões não sejam relevantes, mas elas nos parecem passar ao largo dos problemas centrais que efetivamente impedem que as pessoas se "envolvam com livros" e "compreendam os textos".

Mesmo o aspecto propriamente pedagógico ficou reduzido à sua face psicológica (ou psicologizante) e ao engajamento pessoal, já que, nas palavras de Girotto e Souza (2010, p. 46-47), a perspectiva de se trabalhar com as estratégias de leitura para ensinar os alunos a compreender o que leem "traz como base a metacognição", entendida como "o conhecimento sobre o processo de pensar". Para as autoras, ainda: "o ensino para compreensão é mais efetivo quando acontece na estrutura do letramento ativo" e "salas de aula que promovem o 
letramento ativo têm alunos entusiasmados e interessados, pois os professores não são os únicos a falar e dar opiniões".

\section{Considerações finais}

No início de nossa argumentação, recuperamos o pensamento gramsciano, para o qual é muito comum que um determinado grupo social, que está numa situação de subordinação com relação a outro grupo, adotar a concepção do mundo deste, mesmo que ela esteja em contradição com a sua atividade prática.

Os professores brasileiros têm uma formação docente e condições de trabalho muito aquém do mínimo desejável; trabalham em escolas públicas com condições estruturais nem sempre favoráveis; seus alunos são os filhos da classe trabalhadora ou da classe que, de tão espoliada, nem mesmo consegue trabalho (haja vista o crescente número de subempregados ou desocupados...); ensinam leitura onde não há bibliotecas escolares ou bibliotecas públicas de qualidade... E uma das perspectivas pedagógicas em vias de hegemonização no Brasil assumida em milhares de trabalhos científicos publicados e no documento oficial que estabelece uma base nacional curricular para todas as redes e escolas - defende que se resolverão os problemas de compreensão de textos por meio de estratégias (meta)cognitivas de automonitoramento.

Como pontuado a partir de Alves (2010) e Gramsci (1978a; 1978b), uma concepção de mundo imposta mecanicamente pelo ambiente exterior é desprovida de consciência crítica e coerência, é desagregada e ocasional. Para o filósofo italiano, a adoção acrítica de uma concepção do mundo de outro grupo social resulta um contraste entre o pensar e o agir; por sua vez, a consciência crítica é obtida através de uma disputa de hegemonias contrastantes - e aqui procuramos apresentar, com rigor analítico, o que fundamenta as "Estratégias de Leitura" à luz de um referencial epistemológico para o qual a realidade concreta é o critério de validade de qualquer elaboração teórica e, portanto, de qualquer proposta metodológica para a prática educativa.

Demonstramos que a centralidade conferida à dimensão (meta)cognitiva da leitura escamoteia elementos incontornáveis - e sinalizamos que esse encobrimento, ainda que não seja consciente ou mal-intencionado, redunda na falta de clareza quanto às reais causas do baixo desempenho das crianças nas atividades de leitura. Olhar essas causas exigiria uma fundamentação e uma orientação para a prática educativa que tivesse como premissa o enfrentamento e a superação da desigualdade, ocasionada por um modo de produção e 
distribuição de riquezas que não está realmente preocupado com o máximo desenvolvimento das potencialidades de todas as pessoas.

Essa ênfase nas questões de cunho psicológico ou (meta)cognitivo em detrimento de fatores culturais, econômicos, históricos e sociais, de um lado, e em detrimento de fatores propriamente pedagógicos, de outro, é explicado em termos macropolíticos por Saviani (2010), quando ele apresenta algumas categorias que caracterizariam o pensamento pedagógico atual. Para o professor, são elas:

[...] a) neoprodutivismo, que subverte as bases sócio-econômicas que o pensamento pedagógico buscava encontrar nas ciências sociais; b) neoescolanovismo, que metamorfoseia as bases didáticas que se procurava definir pela pedagogia entendida como ciência da educação; e c) neoconstrutuvismo, que faz refluir as bases psicopedagógicas que se buscava construir pelas investigações da ciência psicológica (SAVIANI, 2010, p. 19).

Ou seja, conforme Saviani (2010), antes, a escolarização se caracterizava como uma preparação da mão-de-obra para ocupar postos de trabalho definidos num mercado que se expandia em direção ao pleno emprego; agora é o indivíduo que terá que adquirir os meios que lhe permitam ser competitivo no mercado de trabalho precarizado e com direitos cada vez mais rarefeitos, de modo que a educação passa a ser entendida como um investimento em capital humano individual. Nessa tendência contemporânea, haveria, pois, a exigência de se alcançar patamares cada vez mais altos de desempenho e produtividade - donde a importância de o sujeito "internalizar" e "automatizar" sua autorregulagem, ou seja, monitorar o próprio processo de leitura por meio da aplicação de "estratégias" definidas de antemão e aplicáveis a quaisquer textos em quaisquer contextos de leitura.

No que concerne ao neoescolanovismo, Saviani (2010) pontua que, neste cenário de instabilidade para o trabalhador e para o próprio trabalho, houve uma ressignificação do lema “aprender a aprender” em relação à sua elaboração originária, no escolanovismo.

Essa visão [que ressignificou o escolanovismo] se propagou amplamente na década de 1990, como se pode constatar pela sua forte presença no "Relatório Jacques Delors", publicado pela UNESCO em 1996, como resultado dos trabalhos da comissão que, entre 1993 e 1996 se dedicou a traçar as linhas orientadoras da educação mundial no século XXI.

Essa mesma orientação foi assumida como política de Estado por meio dos Parâmetros Curriculares Nacionais (PCN) elaborados por iniciativa do MEC para servir de referência à montagem dos currículos de todas as escolas do país [...].

Assim, por inspiração do neoescolanovismo, delinearam-se as bases didático-pedagógicas das novas ideias que vêm orientando as reformas e as práticas educativas desde a década de 1990. Tais práticas se manifestam com características "light", espraiando-se por diferentes espaços, desde as escolas 
propriamente ditas, [...] sem maiores exigências de precisão conceitual e rigor científico (SAVIANI, 2010, p. 22).

Parece indubitável que as imprecisões conceituais, apontadas ao longo deste texto, na apresentação das "Estratégias de Leituras" (por aqueles mesmos que as prescrevem) evidenciam a ausência de rigor e precisão científica apontadas por Saviani como caraterísticas do neoescolanovismo.

Por fim, conforme Saviani (2010, p. 24, grifo do autor), “o neoconstrutivismo se funde com o neopragmatismo e as competências resultam assimiladas aos 'mecanismos adaptativos do comportamento humano' [...] Para a adaptação ao meio natural e material entrariam em cena as competências cognitivas”. Nesse contexto:

[...] tanto a pesquisa como o ensino são legitimados pelo desempenho, isto é, a pesquisa já não visa, propriamente, ao conhecimento desinteressado da verdade e o ensino não se centra mais na formação de um modelo de vida; considerando, portanto, que, conforme esse entendimento, conhecer não implica voltar-se para a realidade visando compreendê-la e explicá-la, mas construir modelos e simular virtualmente o funcionamento desses modelos (SAVIANI, 2010, p. 25).

Assim, considerando que nosso objetivo era apresentar e responder ao questionamento sobre a pertinência e a consistência do trabalho pedagógico com a leitura orientado pelas "Estratégias de Leitura", face à análise da realidade objetiva, parece pertinente concluir que a resposta é negativa - e não se trata apenas de uma diferença de orientação epistemológica, com seu espraiamento para os campos linguístico-literário ou pedagógico: embora isso seja relevante, quando se pensa na defesa da classe que vive do trabalho que é a classe à qual também pertencem os professores em atuação na rede pública brasileira. Trata-se, propriamente, de fragilidades conceituais evidenciadas a partir da análise crítica de documentos e referências bibliográficas. Nesse sentido, parece-nos que, para resolver os problemas do ensino de leitura no Brasil, e particularmente do ensino de leitura literária, o trabalho pedagógico orientado pela “internalização e automatização" de estratégias (meta)cognitivas de leitura precisa ser superado.

\section{REFERÊNCIAS}

ALVES, A. R. C. O conceito de hegemonia: de Gramsci a Laclau e Mouffe. Lua Nova, São Paulo (SP), n. 80, p. 71-96, 2010. Disponível em: https://www.scielo.br/pdf/ln/n80/04.pdf. Acesso em: 20 out. 2020. 
BRASIL. Ministério da Educação. Base Nacional Comum Curricular. Brasília, DF: MEC, 2018. Disponível em:

http://basenacionalcomum.mec.gov.br/images/BNCC_EI_EF_110518_versaofinal_site.pdf. Acesso em: 20 out. 2020.

BRASIL. Ministério da Educação. Secretaria de Alfabetização. Política Nacional de Alfabetização. Brasília, DF: MEC, SEALF, 2019.

DAVIS, L. Prefácio. In: MENIN, A. M. C. S. et al. (Eds.). Ler e compreender: estratégias de leitura. Campinas, SP: Mercado de Letras, 2010. p. 9-11.

ECONOMIA. Salário mínimo em agosto deveria ter sido de R\$ 4.536,12, calcula Dieese. Disponível em: https:/economia.uol.com.br/noticias/redacao/2020/09/04/salario-minimo-emagosto-deveria-ter-sido-de-r-453612-calcula-dieese.htm. Acesso em: 21 out. 2020.

GIROTTO, C. G. G. S.; SOUZA, R. J. Estratégias de leitura: para ensinar alunos a compreender o que leem. In: MENIN, A. M. C. S. et al. (Eds.). Ler e compreender: estratégias de leitura. Campinas, SP: Mercado de Letras, 2010. p. 45-114. GRAMSCI, A. Concepção dialética da história. Rio de Janeiro, RJ: Civilização Brasileira, 1978a.

GRAMSCI, A. Os intelectuais e a organização da cultura. Rio de Janeiro, RJ: Civilização Brasileira, 1978b.

GRUPPI, L. O conceito de hegemonia em Gramsci. 3. ed. Rio de Janeiro, RJ: Graal, 1991.

INDEX MUNDI. Taxa de alfabetização - Mundo. Disponível em:

https://www.indexmundi.com/map/?v=39\&l=pt, Acesso em: 24 mar. 2021.

MACCIOCHI, M. A. A favor de Gramsci. Rio de Janeiro, RJ: Paz e Terra, 1976.

MENIN, A. M. C. S. et al. Ler e compreender: estratégias de leitura. Campinas, SP:

Mercado de Letras, 2010.

OHANA, V. IBGE: $2,7 \%$ das famílias ganham um quinto de toda a renda no Brasil. Carta Capital, 04 out. 2019. Disponível em: https://www.cartacapital.com.br/sociedade/ibge-27das-familias-ganham-um-quinto-de-toda-a-renda-no-brasil/. Acesso em: 21 out. 2020.

SAVIANI, D. Ciência e educação na sociedade contemporânea: desafios a partir da pedagogia histórico-crítica. Revista Faz Ciência, Francisco Beltrão (PR), v. 12, n. 16, p. 13-36, jul./dez. 2010. Disponível em: http://e-revista.unioeste.br/index.php/fazciencia/article/view/7434.

Acesso em: 21 out. 2020.

TV JORNAL. IBGE: 2020 tem recorde de desemprego no Brasil. 11 ago. 2020. Disponível em: https://tvjornal.ne10.uol.com.br/noticias/2020/08/11/ibge-2020-tem-recorde-dedesemprego-no-brasil. Acesso em: 21 out. 2020 


\section{Como referenciar este artigo}

DALVI, M. A.; PONCE, R. F. Didática da literatura: problematização de uma tendência em vias de hegemonização. Revista Ibero-Americana de Estudos em Educação, Araraquara, v. 16, n. esp. 3, p. 1662-1680, jun. 2021. e-ISSN: 1982-5587. DOI: https://doi.org/10.21723/riaee.v16iesp.3.15304

Submissão em: 05/02/2021

Revisões requeridas em: 30/03/2021

Aprovado em: 12/05/2021

Publicado em: 01/06/2021 